
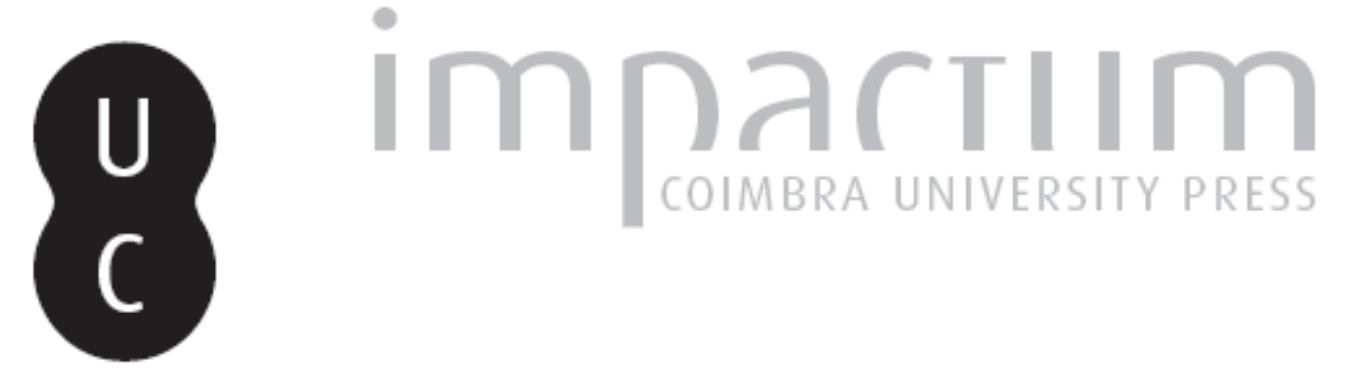
The Alcoitão rehabilitation school and the scientific and professional assertion of the
physiotherapist in Portugal in the second half of the 20th century

Autor(es): $\quad$ Rodrigues, Maria Armanda; Pita, João Rui; Pereira, Ana Leonor

Publicado por: Imprensa da Universidade de Coimbra

URL

persistente:

URI:http://hdl.handle.net/10316.2/36840

DOI:

DOI:http://dx.doi.org/10.14195/1647-8622_14_14

Accessed : $\quad$ 26-Apr-2023 09:05:08

A navegação consulta e descarregamento dos títulos inseridos nas Bibliotecas Digitais UC Digitalis, UC Pombalina e UC Impactum, pressupõem a aceitação plena e sem reservas dos Termos e Condições de Uso destas Bibliotecas Digitais, disponíveis em https://digitalis.uc.pt/pt-pt/termos.

Conforme exposto nos referidos Termos e Condições de Uso, o descarregamento de títulos de acesso restrito requer uma licença válida de autorização devendo o utilizador aceder ao(s) documento(s) a partir de um endereço de IP da instituição detentora da supramencionada licença.

Ao utilizador é apenas permitido o descarregamento para uso pessoal, pelo que o emprego do(s) título(s) descarregado(s) para outro fim, designadamente comercial, carece de autorização do respetivo autor ou editor da obra.

Na medida em que todas as obras da UC Digitalis se encontram protegidas pelo Código do Direito de Autor e Direitos Conexos e demais legislação aplicável, toda a cópia, parcial ou total, deste documento, nos casos em que é legalmente admitida, deverá conter ou fazer-se acompanhar por este aviso.

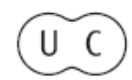




\section{educação e democracia}

ESTUD OSD OSÉCULO

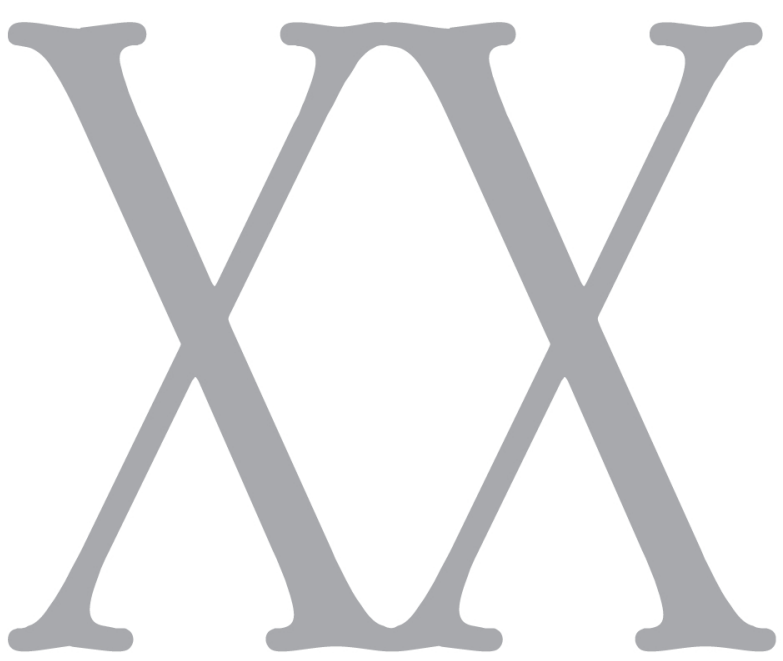

número 14 • 2014

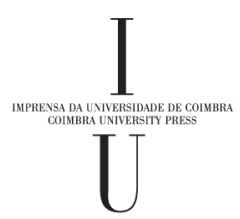




\section{A ESCOLA DO ALCOITÃO E A AFIRMAÇÃO CIENTÍFICA E PROFISSIONAL DO FISIOTERAPEUTA EM PORTUGAL NA SEGUNDA METADE DO SÉCULO XX}

Maria Armanda Rodrigues

João Rui Pita

Ana Leonor Pereira 
Maria Armanda Rodrigues, Licenciada em Fisioterapia - Escola Superior de Saúde do Alcoitấo. Investigadora do CEIS20, Grupo de História e Sociologia da Ciência e da Tecnologia. Bolseira de Doutoramento da FCT - FFUC. E-mail: armandarod@gmail.com

Ana Leonor Pereira, Doutora em História (História da Cultura, tese em História da Cultura Científica) pela FLUC. Professora Auxiliar da Faculdade de Letras da Universidade de Coimbra. Investigadora e Co-Coordenadora do Grupo de História e Sociologia da Ciência e da Tecnologia do CEIS20. E-mail: aleop@ci.uc.pt

João Rui Pita, Doutor em Farmácia (tese em História da Farmácia); Agregado em Sociofarmácia (História da Farmácia) - Universidade de Coimbra. Professor Associado com Agregação da Faculdade de Farmácia da Universidade de Coimbra. Investigador e Co-Coordenador do Grupo de História e Sociologia da Ciência e da Tecnologia do CEIS20. E-mail: jrpita@ci.uc.pt 


\section{Introdução}

Grande parte dos meios utilizados em Fisioterapia têm uma longa história ${ }^{1}$, muitas vezes coincidente com a história das práticas de saúde no decurso da história da humanidade ${ }^{2}$. Esses meios têm sido usados e as técnicas aplicadas por pessoas cujo título académico e estatuto profissional variaram ao longo da história ${ }^{3}$.

$\mathrm{Na}$ chamada época contemporânea (séculos XVIII-XX), nos Estados Unidos da América, em países da Grã-Bretanha e até em Portugal cedo se relacionou a utilização desses meios e técnicas com conflitos bélicos. Datam de finais do século XVIII e início do século XIX as primeiras publicações militares que versavam a recuperação da condição física e da saúde através de técnicas aplicadas por profissionais muito mais tarde denominados fisioterapeutas ${ }^{4}$.

Também se deve sublinhar que até então o recurso a agentes físicos e aos movimentos eram práticas recorrentes tendo ficado célebre a cura pelo movimento, de Ling5. A poliomielite, doença antiga, mas que marcou em particular a história recente do século XX, proporcionou o desenvolvimento das ajudas técnicas, essencialmente cadeiras de rodas e próteses e parece ter sido decisiva em vários países para a valorização do papel profissional do fisioterapeuta.

São escassos os estudos historiográficos sobre a história da fisioterapia em Portugal não havendo igualmente estudos científicos sobre a história da fisioterapia em Portugal no período dos conflitos militares. Contudo, podemos considerar que Portugal, tal como outros países, foi influenciado pelos conflitos internacionais, mesmo por aqueles conflitos onde o seu envolvimento não foi de primeira linha.

Em Portugal existem desde o início do séc. XX referências a grupos de profissionais médicos e não médicos que se ocupavam da reabilitaçáo física. Os médicos tinham a formação em medicina embora sem qualquer especialização em fisioterapia. Havia outros profissionais que exerciam a actividade obtendo, por vezes, uma formação específica,

${ }^{1} \mathrm{O}$ presente estudo integra-se no projecto de tese de doutoramento "A fisioterapia em Portugal no século XX: ciência, técnica e profissão” (FCT-SFRH/BD/66282/2009) e no projecto de investigação "Internacionalización y estrategias contra la enfermedad: profesionales, personas afectadas y activismo ante la erradicación de la polio y la aparición del SPP (1963-2010)", HAR2012-39655-C04-03 (Ministério de Economia y Competitividad-España. Integram-se no âmbito das actividades de investigação do Grupo de História e Sociologia da Ciência e da Tecnologia do Centro de Estudos Interdisciplinares do Século XX da Universidade de Coimbra. FCT- PEST-OE/HIS/UI0460/2014

${ }^{2}$ Veja-se a este propósito o estudo de GRANGER, F. B. - "The development oh the physiotherapy". Physical Therapy. 56:1(1976), pp. 13-14.

${ }^{3}$ Este assunto encontra-se bem explorado na dissertação: MCOY, P. — "Physiotherapy: A profession?" Belfast: Dissertation submited as a part fulfilment for the degree of Master of education at Queen's University,1987.

${ }^{4}$ Veja-se: BARCLAY, J. — "In Good Hands: The story of the Chartered Society of Physiotherapy", 1894-1994. Oxford: Butterworth-Heinemann, 1994.

${ }^{5}$ Trata-se de um processo pensado e organizado por Per Henrik Ling (1776-1839) considerado como fundador da educação física moderna e do sistema de massagem sueca. Para o inventor deste processo, a ginástica tinha que ver essencialmente com finalidades médicas, militares, estéticas e educativas. 
embora pouco sistematizada e de curta duração. Alguns dos que obtinham aquela formação tinham, por vezes, uma outra anterior - a enfermagem. No presente estudo abordaremos as etapas mais relevantes da formação dos fisioterapeutas em Portugal.

\section{Algumas balizas legislativas e regulamentares na segunda metade do século XX}

Em 1953 a portaria 14416, de 9 de Junho apresenta a criação de "cursos especiais" de ajudantes técnicos de radiologia e de fisioterapia (art. 37º) com a duração de um ano.

A formação de profissionais não médicos designados fisioterapeutas surgiu no ano de 1957, através dos cursos de reabilitação de agentes técnicas de fisioterapia criados pela Santa Casa da Misericórdia de Lisboa. A partir desta data a Santa Casa da Misericórdia de Lisboa torna-se um marco importante no processo de formação de fisioterapeutas e, por conseguinte, no ensino da fisioterapia, tendo construído o primeiro Centro de Medicina de Reabilitação.

Com efeito, em 1956, com o Provedor o Dr. António Madeira Pinto, a Santa Casa da Misericórdia de Lisboa decidiu dar início à construção de um centro de reabilitação, com características inovadoras no panorama nacional, inspirando-se em experiências estrangeiras nesse domínio. Este empreendimento foi planeado metodicamente promovendo-se, antes mesmo da construção do estabelecimento, a criação dos meios para o seu eficiente funcionamento, sobretudo no que diz respeito à preparação do pessoal técnico especializado que não tinha formação adequada.

Assim, a Santa Casa da Misericórdia de Lisboa lançou no início de 1957, os primeiros cursos de formação de terapeutas, estabelecendo que os seus programas de ensino obedeceriam aos níveis exigidos pelas normas internacionais de então, recorrendo a docentes nacionais e estrangeiros.

Desta acção pioneira da Santa Casa da Misericórdia de Lisboa resultou a criação da Escola de Reabilitação do Alcoitão, através da Portaria 22034, de 4 de Junho de 1966, do Ministério da Saúde e Assistência, ficando sediada no Centro de Medicina de Reabilitação de Alcoitão, que havia sido inaugurado nesse mesmo ano.

Como forma de tornar lucrativas as infraestruturas, esta Portaria previa no seu preâmbulo a necessidade de formar adequadamente o pessoal técnico especializado, acrescentado um terceiro grupo aos já existentes, o grupo do pessoal técnico de reabilitação, indicados no no 1 da Portaria 18523 de 12 de Junho de 1961.

Consequentemente a Portaria 22034, de 4 de Junho 1966, marca a introdução oficial do título profissional de fisioterapeuta, em Portugal, a que passaram a ter acesso os diplomados pela Escola de Reabilitação do Alcoitão da Santa Casa da Misericórdia de Lisboa ou por outras, de igual condição, que viessem a ser criadas.

Em 1975 foi criado o primeiro Estatuto Provisório da Escola e do Conselho Diretivo Provisório. Este documento marcou uma separação pedagógica entre a Escola de Reabilitação do Alcoitão e o Centro de Medicina de Reabilitaçáo de Alcoitão, sem contudo, haver uma total divisão financeira e administrativa. 
A 15 de Novembro de 1977, pelo Decreto-Lei no 480/77, a dependência da Escola passa da Santa Casa da Misericórdia para o Ministério dos Assuntos Sociais e é confirmado a título provisório o Conselho Diretivo da Escola. Esta modificação relaciona-se com o facto do Centro de Medicina de Reabilitação de Alcoitão, ao qual a escola esteve associada desde o início da sua criação, ter passado a integrar a rede do sector público.

Em 1982 através do Decreto-Lei no 371/82, de 10 de Setembro a tutela pedagógica da Escola passou para o Departamento de Recursos Humanos da Saúde do Ministério da Saúde. A escola passou a estar abrangida pela mesma legislação que regia as Escolas Técnicas dos Serviços de Saúde, de Lisboa, Porto e Coimbra.

Apesar da alteração da tutela, a Escola de Reabilitação do Alcoitão continuou a gozar de autonomia na gestáo pedagógica, o que lhe permitiu manter o modelo de formação que vinha desenvolvendo.

Em 1990, após um processo de revisão curricular realizado no conjunto das escolas nacionais atrás citadas, conduzido pelo Departamento de Recursos Humanos do Ministério da Saúde foram aprovados planos de estudos iguais a nível nacional, que passaram a vigorar obrigatoriamente em todas as escolas públicas. Neste processo, a liderança da revisão curricular do curso de Fisioterapia coube à Escola de Reabilitaçáo do Alcoitáo, pelo que o novo currículo pode ser entendido não como um corte, mas antes como uma ampliação do modelo então em vigor.

Esta revisáo curricular realizada pelo Ministério da Saúde visava preparar a integração destes cursos no ensino superior tal como tinha sido pensado logo desde inicio pelo Dr. Santana Carlos.

Em 1991 iniciou-se uma nova fase da história deste estabelecimento de ensino com o seu retorno ao estatuto de natureza privada, sendo reintegrado na Santa Casa da Misericórdia de Lisboa pelo Decreto-Lei no 274/91, de 7 de Agosto, com a confirmação do Conselho de Direção. Manteve-se contudo a dependência financeira e administrativa do Centro de Medicina de Reabilitação de Alcoitão.

$\mathrm{Na}$ altura iniciou-se o processo tendente à integração da Escola no Ensino Superior Politécnico e a preparação da sua autonomia relativamente ao Centro de Medicina de Reabilitação de Alcoitão. Este movimento é coincidente com o da integração das Escolas Técnicas dos Serviços de Saúde no Ensino Superior Politécnico, o qual viria a efetivar-se através do Decreto-Lei no 415/93, de 23 de Dezembro, que criou as Escolas Superiores de Tecnologia da Saúde de Lisboa, Porto e Coimbra.

A integraçáo plena no sistema de ensino a nível do Ensino Superior aconteceu em 1994, com a reconversão da Escola de Reabilitação do Alcoitáo em estabelecimento de ensino superior privado e com a aprovaçáo dos planos de estudos, atribuindo o grau de bacharel de acordo com o primeiro estatuto da Escola de Reabilitação do Alcoitão, ao abrigo da legislação em vigor.

A partir dessa data, já com o estatuto de escola de ensino superior politécnico, foi possível assinalar, também, alguns outros marcos relevantes deste estabelecimento de ensino. Assim, em 1995 foi aprovado e feito o registo do segundo estatuto da Escola Superior de Saúde do Alcoitão, ao abrigo da legislação em vigor. Três anos mais tarde, 
em 1998, são publicados os Estatutos da Escola Superior de Saúde do Alcoitão e o Regulamento da Carreira Docente, em Diário da República - II Série - Aviso no 15 935/98 (2a série), no 232 de 08-10-1998.

Em 2000 é autorizado o funcionamento dos cursos bietápicos de licenciatura e quatro anos mais tarde é publicada a alteração aos Estatutos da Escola Superior de Saúde do Alcoitão, em Diário da República - II Série - Aviso no 3422/2004 (2a série) no 64 de 16 de Março.

A adaptação dos planos de estudos do curso de licenciatura ao Processo de Bolonha ocorreu no ano letivo 2008/2009. Com o Processo de Bolonha abriu-se a possibilidade da Escola Superior de Saúde do Alcoitão iniciar de forma autónoma a lecionação de curso de mestrado em Fisioterapia, o qual foi autorizado a partir do ano letivo 20092010. O atual estatuto da Escola Superior de Saúde do Alcoitão está então adequado ao novo regime jurídico das instituiçóes de ensino superior.

\section{O projecto da formação de fisioterapeutas}

No arquivo da Santa Casa da Misericórdia de Lisboa encontrámos o registo de uma carta enviada pelo entáo Provedor (1949-1956), Dr. António Madeira Pinto, ao Dr. José de Melo e Castro $^{6}$, subsecretário de Estado da Assistência Social com indicação "urgente" e datada de 30 de Julho de 1955. Dessa carta consta o seguinte: "Convém chamar imediatamente o Dr. Farmhouse ${ }^{7}$ e, com ele, estudar outra hipótese para a instalação rápida do Centro Experimental de Recuperação de Inválidos, na Parede, em vez de São Roque". Mesmo antes de se tornar Provedor, o Dr. José de Melo e Castro tinha em mente a construçáo de um espaço a que vai chamando em muitos documentos de, por exemplo, "Centro de recuperação de incapacitados motores", "Centro de Recuperação de inválidos”. A ideia inicial era aproveitar o Hospital de São Roque para início experimental deste projeto, o que náo aconteceu devido às limitaçóes do espaço e ao valor avultado da obra. Uma segunda hipótese que foi pensada para o avanço do projeto tinha como instituição de acolhimento o Hospital de Sant'Ana ${ }^{8}$. Esta

\footnotetext{
${ }^{6}$ Natural da Covilhá, licencia-se em Direito na Universidade de Coimbra. Exerceu o cargo de Governador Civil de Setúbal entre 1944-1947, sendo deputado pelo mesmo distrito de 1948 a 1954. Em 3 de Junho de 1957 com a remodelação que ocorreu no Governo, é exonerado como Subsecretário de Estado da Assistência Social. Vocacionado para os problemas da assistência pública, deu um forte incremento ao pelouro governativo a seu cargo, cabendo-lhe a feitura do Decreto-Lei no 40 397, de 24 de Novembro de 1955, que reorganizava os serviços da SCML. Tornou-se assim natural a sua nomeação a 15 de Outubro de 1957, para a Provedoria da mesma Santa Casa. Acabaria de ser exonerado deste cargo em Dezembro de 1963.

${ }^{7}$ Médico-Auxiliar, Dr. Manuel João dos Santos Afonso Farmhouse, responsável por várias obras da SCML, de entre as quais destacamos as levadas a cabo no Hospital de São Roque e Hospital de Sant'Ana.

${ }^{8}$ Inaugurado em 31 de Julho de 1931, com lançamento da "primeira pedra" a 7 de Agosto de 1901. Não ficou concluído à data da inauguração, tendo os trabalhos continuado por vários anos. Foi construído para tratar doentes carenciados sendo necessário apresentar o atestado de pobreza para ser admitido. A ideia foi lançada pelo casal Biester e pelo médico assistente Sousa Martins. Sendo os primeiros os benfeitores desta obra que acaba por passar a ser encargo da SCML em 1927.
} 
possibilidade também foi abandonada apesar de vários aspetos favoráveis, como a localização e a possibilidade de aquisição de mais terreno em redor para alargamento da instalação. É de salientar que apesar deste não ter sido o espaço escolhido para esta construção de significativa dimensão, coube ao Dr. Melo e Castro a sua reorganização, tendo passado este espaço a dispor de 300 camas para internamento.

Em sessão de 30 de Janeiro de 1957, Deliberação (Del.) 11 a da mesa da Santa Casa da Misericórdia de Lisboa podemos ler o seguinte: "Tendo-se encontrado terrenos apropriados para a instalação dos referidos estabelecimentos, situados dum e outro lado da estrada de Alcoitão a Alcabideche, com áreas de cerca de 92:000 $\mathrm{m}^{2}$ o situado a norte da mesma estrada e com $66: 500 \mathrm{~m}^{2}$ o localizado a sul, cuja aquisição poderá fazer-se por cerca de 1.600.000\$00, foi deliberado solicitar ao Ministério das Finanças a indicação de um perito avaliador para estimar os citados terrenos". Pouco tempo depois na 16 a sessão de 17 de Abril de 1957, Del. 10a "é deliberada a aquisição de duas parcelas de terreno destinada à Instalação do Centro de Reabilitação de Diminuídos Motores e de outros estabelecimentos". Esta aquisição foi bastante rápida tendo-se consumado no mês seguinte.

Em 27 de Março do mesmo ano na Sessão 13a Del. 29a refere-se o papel do médico Vitor Santana Carlos9. De acordo com o mesmo documento inscreve-se o seguinte: "Está a funcionar nas Casas de São Vicente de Paulo, um curso preparatório de agentes técnicas de fisioterapia e terapêutica ocupacional, destinadas ao Centro de Reabilitação de Diminuídos Motores a instalar por esta Misericórdia e torna-se necessário que da direção do curso fique encarregado o aludido médico, que pertence ao quadro dos médicos escolares da Direcção-Geral dos Desportos, Educação Física e Saúde Escolar, do Ministério da Educação Nacional”. Vitor Santana Carlos viria a fazer parte da Comissão Instaladora do Centro de Reabilitação de Diminuídos Motores que reuniu pela primeira vez, na sede dos Cursos de Reabilitação, a 19 de Janeiro de 1961 como se pode ver no Livro de Actas 1961-1966 da referida Comissão Instaladora. Neste documento lê-se: "Estavam presentes todos os membros da Comissão, a saber: Engenheiro Jaime Pereira Gomes, Arquiteto Formosinho Sanchez ${ }^{10}$, Dr. Victor Santana Carlos, Dr. Jorge Santos, Enfermeira D. Maria da Graça de Azevedo Coutinho Simeão, Dra D. Maria Adelina Cercas Colaço, servindo de secretária Maria Amélia de Azevedo Vaz Pinto Cyrne de Castro”. Tratava-se de uma

\footnotetext{
${ }^{9}$ Em 18-11-1954, num breve currículo apresentado na candidatura ao curso que viria a terminar em 1958 acumulam-se alguns cargos significativos para a época como: o de Médico-chefe de serviço de Fisioterapia do Instituto Português de Reumatologia (que fazia gratuitamente desde 1951), professor na escola de Enfermagem de S. Vicente de Paulo (desde 1949), professor no Instituto Social (desde 1949), Médico Fisioterapeuta da Federação de Caixas da Previdência e do Hospital de Trabalho Venerável Ordem Terceira de São Francisco da Cidade. Publicou vários trabalhos sobre a especialidade médica e fez várias comissóes em Portugal e no estrangeiro. Em 1958, terminou o seu curso de 3 anos, como residente de Medicina Física e Reabilitação, nos hospitais da Universidade de Nova-York, sob a direção do Dr. Howard A. Rusk.

${ }^{10} \mathrm{O}$ arquitecto Formosinho Sanchez (1922-2004) foi prestigiado arquiteto português e professor de arquitetura sublinhando-se, entre várias obras, algumas que realizou no campo das instituições assistenciais como Hospital e balneário das Caldas de Monchique, a Casa de Saúde da Cruz Vermelha (Lisboa), o Hospital de Miranda do Douro.
} 
comissão que integrava pessoas de diversas proveniências profissionais, não só relacionadas com a saúde mas também com a conceção do próprio edifício.

O exemplo de hospitais franceses e ingleses e por vezes americanos foi referido várias vezes ao longo das atas para explicar o trabalho que tinha de ser realizado em Portugal. Os mentores do projeto reconheciam que o recurso a instituiçóes com valor científico e técnico na área era relevante para a institucionalização deste domínio das ciências e tecnologias da saúde. O Arquiteto Formosinho Sanchez visitou vários hospitais nestes países antes e durante a execução do projeto tal como outras figuras como Filipe Charters Oliveira ${ }^{11}$, Santana Carlos, Ma Luísa Conde Pereira ${ }^{12}$. Foram vários os que se deslocaram ao estrangeiro para realizar estágios e fazer especializaçóes. Em causa estavam critérios de ordem institucional, científicos e organizacionais e também parâmetros de ordem prática clínica.

Em 2 de Julho de 1966, após cinco anos de trabalhos intensos, o Centro de Medicina de Reabilitação de Alcoitão foi solenemente inaugurado com a presença do Presidente da República, Almirante Américo Tomás, tendo havido considerável difusão do acontecimento na imprensa. A organizaçáo da instituiçáo, as balizas regulamentares, os apoios particulares e oficiais definiram claramente os objetivos principais da instituição que passaram a ser muito claros: a reabilitaçáo de pessoas com incapacidade motora e a formação de pessoal especializado.

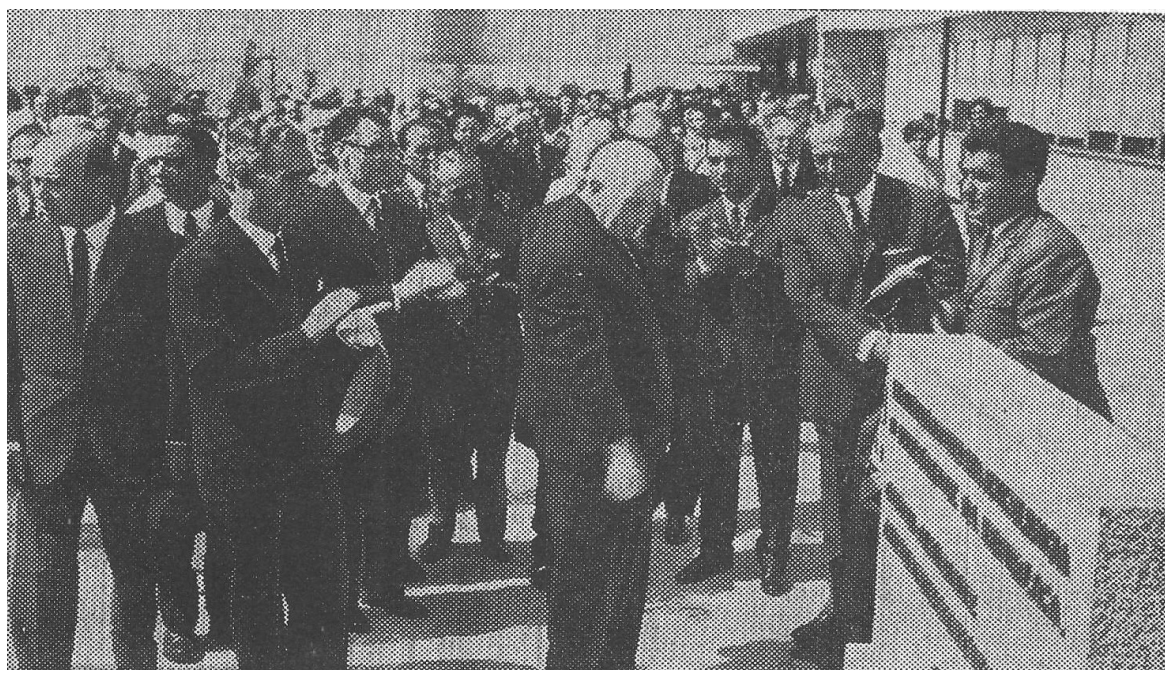

Imagem 1. Inauguraçáo do Centro de Medicina do Alcoitão

Diário de Noticias 3-7-1966, p. 10.

\footnotetext{
${ }^{11}$ Filipe Charters Lopes Vieira da Câmara Oliveira, licenciado em Direito, adjunto do Provedor Dr. António Madeira Sousa Pinto.

${ }^{12}$ Licenciada em Ciências Biológicas pela Faculdade de Ciências da Universidade Clássica de Lisboa, terminou o curso de Enfermagem Geral na Escola de Enfermagem de S. Vicente de Paulo em 1953, foi professora e Subdiretora da Escola de Reabilitação do Alcoitão, de 1957 a 1966.
} 
Os primeiros passos na formação de fisioterapeutas: dos primeiros cursos até à criação da Escola de Reabilitação

Antes da construção do estabelecimento, os mentores do projeto verificaram haver necessidade de criação dos meios eficientes para o seu funcionamento. A vontade dos responsáveis era criar, para além das condiçóes materiais, as melhores condiçóes de recursos humanos e ter os técnicos mais competentes e ajustados ao projeto. Havia que criar os meios mais adequados. Este trabalho anterior ao termo da construçáo foi realizado. Estava sobretudo em causa a preparação de pessoal técnico especializado adequado à recuperação que até à data não existia em Portugal.

Assim, os primeiros cursos de formação de terapeutas, recorrendo a programas de ensino de acordo com os níveis exigidos pelas normas internacionais de então, tiveram início em 1957, tendo havido recurso a formadores estrangeiros. Esta iniciativa foi desenvolvida pela Santa Casa da Misericórdia de Lisboa, com o apoio de alguns médicos influentes. Foi o caso de Santana Carlos que assumia forte protagonismo institucional e científico. As primeiras alunas terminaram a sua formação em Dezembro de 1959.

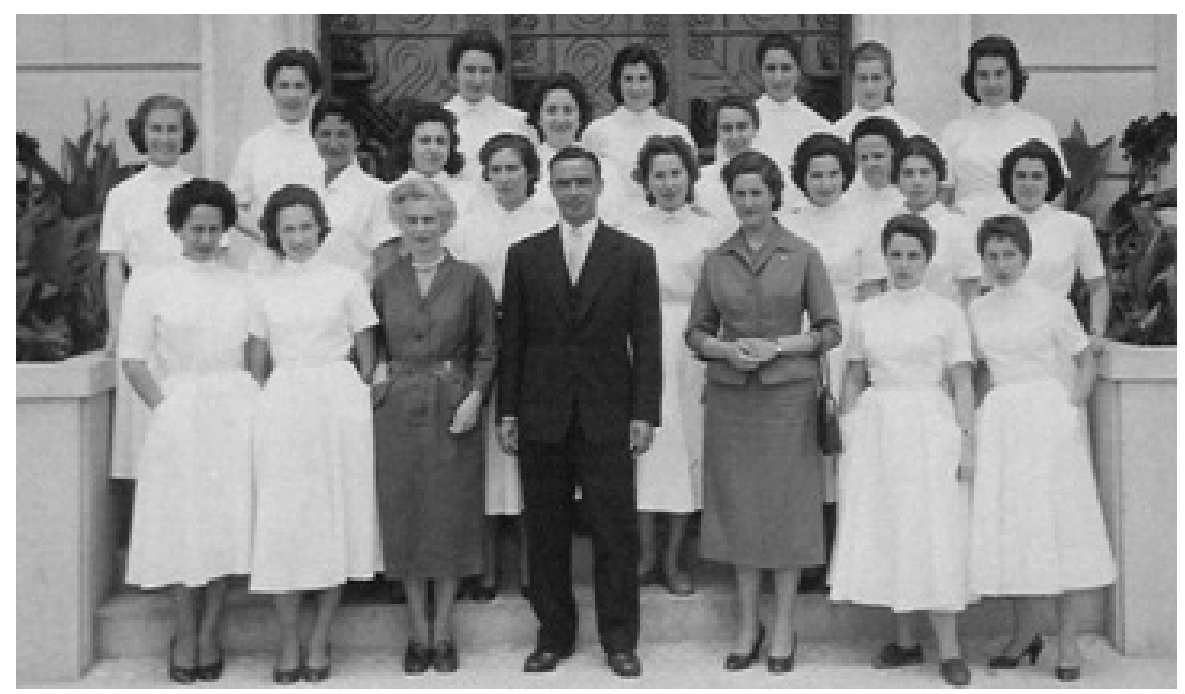

Imagem 2. Foto da primeira turma de fisioterapeutas e terapeutas ocupacionais. Ao centro Santana Carlos, à esquerda $M^{\mathrm{a}}$ Luísa Conde Pereira e à direita Inês Stiwell. Foto do acervo fotográfico do Centro de Estudos do Hospital de Santana.

Este grupo de alunas viria a constituir, em 1960, a Associação Portuguesa de Fisioterapeutas, a qual viria a ser admitida, em 1963, na "World Confederation for Physical Therapy”. A constituição da Associação e a sua inclusão numa federação internacional, que funcionou como reconhecimento nacional e internacional do grupo 
profissional, foi um passo decisivo na profissionalização dos fisioterapeutas portugueses, na sua identidade e um passo imprescindível na sua validação técnica e científica. A primeira presidente da associação foi Inês Stiwell.

Esta iniciativa pioneira da Santa Casa da Misericórdia de Lisboa inaugurou a atividade formativa de fisioterapeutas a nível nacional. O seu rigor técnico e científico acentuou-se com a formação complementar no estrangeiro de alguns dos recémformados. Esta formação internacional tinha também o objectivo de dotar alguns dos profissionais de um conjunto vasto e especializado de saberes adequados ao exercício docente. Estava em causa formar fisioterapeutas para o melhor desempenho profissional e para tanto impunha-se fazer um tal investimento. Deste estado de coisas resultou a criação da Escola de Reabilitação do Alcoitão, através da Portaria 22034, de 4 de Junho de 1966, do Ministério da Saúde e Assistência. A sua sede foi o Centro de Medicina de Reabilitação de Alcoitão e foi inaugurada naquele mesmo ano.

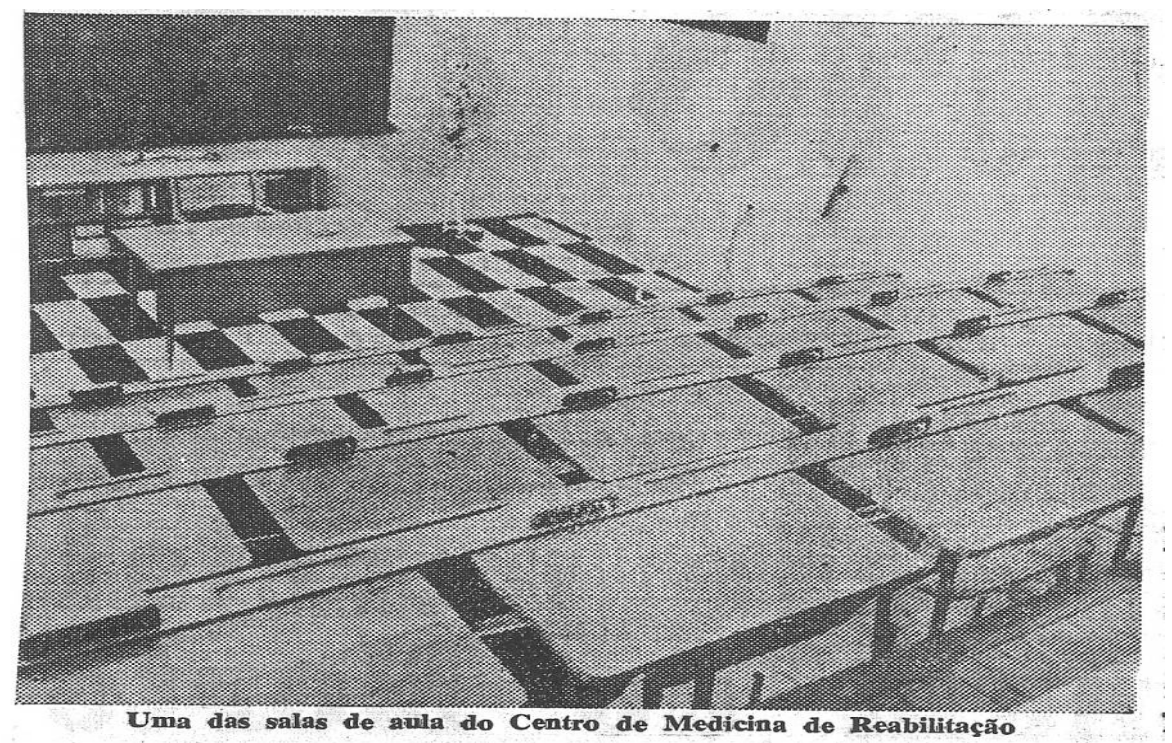

Imagem 3. Inauguração do Centro de Medicina de Reabilitação. Jornal O Século, 1966, p.8.

A introdução oficial em Portugal do título profissional de fisioterapeuta, a que passaram a ter acesso os diplomados pela Escola de Reabilitaçáo da Santa Casa da Misericórdia de Lisboa ou por outras de igual nível que viessem a ser criadas, deu-se através da Portaria atrás citada.

Esta Portaria considerava "...devidamente habilitados com os respetivos títulos profissionais" [ponto 40], os indivíduos que tiveram aprovação final nos Cursos de Reabilitação que a Santa Casa da Misericórdia de Lisboa vinha realizando desde 1957. Esse documento apresenta ainda no seu preâmbulo um plano nacional de serviços de reabilitaçáo e a consequente necessidade de formar adequadamente o "pessoal técnico 
especializado em reabilitação" [preâmbulo da Portaria 22 034, de 4 de Junho de 1966] sem o qual não se poderiam rentabilizar as estruturas que se estavam a desenvolver, sublinhando-se o esforço e o investimento que nesta área estavam a ser feitos pela Santa Casa da Misericórdia de Lisboa.

Desta forma "aos dois grupos de técnicos e auxiliares dos serviços clínicos" indicados no no 1 da Portaria 18523 de 12 de Junho de 1961 é "acrescentado um terceiro grupo, que abrange pessoal técnico de reabilitação, do qual fazem parte os fisioterapeutas, os terapeutas ocupacionais e os terapeutas da fala, habilitados com os cursos correspondentes" [ponto $1^{\circ}$ ].

Contudo, deve salientar-se que, antes do aparecimento desta formação devidamente institucionalizada, no âmbito da fisioterapia, protagonizada pela Escola de Reabilitação do Alcoitão, havia praticantes de determinados processos de fisioterapia. Sobretudo na aplicação dos denominados agentes físicos e de técnicas no domínio dos exercícios terapêuticos e da massagem. Deve assinalar-se que a formação destes praticantes não era muito especializada e que a regulamentaçáo existente era muito precária, ainda que a formação que obtinham fosse tutelada pelos médicos que chefiavam os serviços em que esses praticantes trabalhavam.

A existência de profissionais não médicos praticantes de fisioterapia em instituiçóes oficiais de saúde em Portugal é antiga. Não temos contudo dados suficientes que nos confirmem com exatidão o seu surgimento nos hospitais portugueses. De qualquer modo, assinale-se em 1901 na "Creação e organização de um laboratorio de analyse clinica no Hospital Real de S. José”, no artigo $2^{\circ}$, onde o diploma se reporta às diferentes secçóes do laboratório, a 4a Secção de "Analyse radioscopia, radiographia e

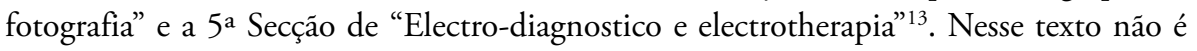
feita qualquer alusão às exigências de formação para os profissionais que haviam de desempenhar o trabalho naquelas secçóes. Mas, em documentos posteriores, verificamos que em alguns hospitais (nomeadamente nos Hospitais Civis de Lisboa) o acesso às funçóes no âmbito da fisioterapia dependia de um concurso de provas práticas, a que só tinham acesso os candidatos habilitados com "exame de prática" e o curso geral de Enfermagem da Escola de Enfermagem Artur Ravara, tal como acontecia com outros profissionais da área da saúde, nomeadamente os auxiliares de preparadores de análises clínicas, ajudante de preparador de anatomia patológica ${ }^{14}$. No relatório do enfermeiromor do mesmo Hospital, o conhecido médico José Curry Cabral ${ }^{15}$, publicado no

\footnotetext{
${ }^{13}$ Trata-se do "Decreto Auctorizando a creação de um laboratório de analyse clinica no referido hospital [Hospital Real de S. José] , e aprovando a respectiva organização, que ao mesmo decreto vae appensa”. Diário do Governo, no 293, de 27 de Dezembro de 1901, p. 3652.

${ }^{14}$ Veja-se, por exemplo, o Decreto-Lei no 28794 de 12 Julho de 1938, $\operatorname{art}^{\circ} 34$, que "reorganiza, em harmonia com as disposiçóes do decreto-lei no 28:115, os quadros dos Hospitais Civis de Lisboa, incluindo os do Manicómio Bombarda e os serviços de hospitalização anti-rábica e anti-diftérica do Instituto Bacteriológico Câmara Pestana”.

${ }^{15}$ Curry Cabral (1844-1920) foi um reputado médico e professor da Escola Médico-Cirúrgica de Lisboa, enfermeiro-mor do Hospital de S. José sendo considerado uma das figuras mais relevantes da medicina
} 
mesmo Diário do Governo, assinala-se que as secçóes de radiologia e de electricidade deveriam ter dois "chefes técnicos" e um "preparador" 16 .

As designaçóes com que estes profissionais que praticavam a fisioterapia aparecem referenciados na época e até aos anos 50 do século XX eram muito variáveis. Por exemplo no Decreto-Lei de 1938 atrás citado, surgem as seguintes categorias dentro do "Serviço de Agentes Físicos - Fisioterapia": desde logo "auxiliares de fisioterapia", depois os "segundos ajudantes técnicos de fisioterapia" e finalmente os "ajudantes técnicos de fisioterapia", não sendo no entanto utilizada a expressão fisioterapeuta.

A designação dos profissionais não nos parece ser apenas uma questão de nomenclatura. Era uma designação que tinha que ver, justamente, com o suporte científico, com a formação dos profissionais pois o processo de profissionalização de uma actividade profissional está intimamente relacionado com o tipo, qualidade e extensão da formação, científica, técnica e outra.

O título de fisioterapeuta foi durante alguns anos utilizado pelos médicos que se interessaram e especializaram neste domínio ${ }^{17}$, termo que viria a ser substituído posteriormente pelo de fisiatra ou especialista em medicina física e reabilitação ${ }^{18}$.

Quanto à formação dos praticantes de fisioterapia não médicos é de destacar a criação em 1953 na Escola de Enfermagem Artur Ravara, em Lisboa, de "Cursos especiais de ajudantes técnicos de fisioterapia" com a duração de um ano ${ }^{19}$. Este é, em princípio, o ensino pioneiro na formaçáo de fisioterapeutas ou daqueles profissionais que vieram mais tarde a originar os fisioterapeutas. Dizemos "em princípio" pois este campo é bastante complexo e sinuoso $^{20}$. Deve sublinhar-se que a regulamentação genérica da formação das profissóes de saúde complementares à medicina e à enfermagem, em moldes modernos e mais completa, data da década de 60 do século XX, através da Portaria 18523 de 12 de Junho de 1961. Este diploma estabeleceu um sistema de formação das profissóes de saúde complementares à medicina e à enfermagem. Logo a abrir, no preâmbulo, o diploma inscreve: "O desenvolvimento das técnicas médicas registado durante os últimos anos obrigou os hospitais centrais e outros estabelecimentos dependentes do Ministério da

da sua geração. Ver a importância de Curry Cabral na medicina portuguesa em M. Ferreira de Mira, História da Medicina Portuguesa. Lisboa: Edição da Empresa Nacional de Publicidade, 1947, p. 391 e ss.

${ }^{16}$ C. Relatorio do enfermeiro-mor José Curry da Camâra Cabral inserto no Diário do Governo no 293, de 27 de Dezembro de 1901, p. 3632.

${ }^{17}$ Veja-se, por exemplo, o citado Decreto-Lei no 28/794 de 12 Julho de 1938.

${ }^{18}$ Este assunto encontra-se bem ilustrado, por exemplo, em artigos publicados em revistas científicas médicas portuguesas. Vejamos apenas alguns escassos exemplos: Formigal Luzes assina como "Encarregado da Consulta de Fisioterapia no Hospital de Santa Maria” (F. Formigal Luzes, "Algumas observaçóes de doentes tratados pelos raios ultra-violetas", Lisboa Médica, 2, 1925, pp. 106-117); A mesma Lisboa Médica noticia a nomeação do médico Francisco Formigal Luzes para professor da cadeira de Fisioterapia do Instituto de Hidrologia (veja-se Lisboa Médica, 8, 1931, p. IV); Vasco Riobom assina artigo como "Interno graduado de Fisioterapia dos H.C.L." (Vasco Riobom, "Atitudes fisioterapêuticas ante a poliomielite”, O Médico, 568, 1962, pp. 158-163).

${ }^{19}$ Veja-se Portaria 14 416, de 9 de Junho de 1953.

20 Temos em curso o levantamento de fontes que possam ser conducentes a uma cronologia mais pormenorizada da formação dos fisioterapeutas em Portugal. 
Saúde e Assistência a criarem, além de escolas de enfermagem, pequenos cursos para preparação dos outros profissionais necessários" ${ }^{21}$. Reconhece o legislador, por isso, a necessidade dos cursos específicos para um conjunto de profissionais. E esses profissionais estavam devidamente estabelecidos no diploma e divididos em dois grupos: "10 Os técnicos e auxiliares dos serviços clínicos distribuem-se por dois grupos. O primeiro é constituído pelos auxiliares de laboratório de análises e de fisioterapia, os encarregados de câmara escura e os ajudantes mistos". O segundo grupo incluía "os dietistas, os técnicos de radiologia e de fisioterapia e os preparadores de análises clínicas”22.

\section{A inovação da Escola de Reabilitaçáo do Alcoitão na formação de fisioterapeutas em Portugal (1966-1980)}

A Portaria 22034, de 4 de Junho de 1966, do Ministério da Saúde e Assistência, refere como habilitação mínima para a admissão aos cursos de reabilitação o antigo 7 o ano dos Liceus, tal como na época era necessário para o acesso ao ensino superior. Outras especificidades foram deixadas para regulamentação posterior.

A Escola de Reabilitação do Alcoitão continuou a ser pautada por padróes internacionais e voltou a ter docentes estrangeiros, tendo sido formado um corpo docente totalmente constituído por portugueses no início da década de 70.

A principal prova do reconhecimento internacional da qualidade do ensino naquela instituição residiu no facto de o Council for Professions Supplementary to Medicine, (organismo que controla, entre outras profissóes, o exercício e a formação dos fisioterapeutas no Reino Unido) ter reconhecido, a partir de 1972, o diploma da Escola como habilitaçáo suficiente para o exercício profissional naquele país, bastando para tanto que o titular do diploma comprovasse simultaneamente a posse de um ano de exercício profissional em Portugal.

Em paralelo, o início da década de 70 foi marcado, por uma reestruturação significativa do sistema de saúde através do Decreto-Lei no 413/71 ${ }^{23}$ e pela publicação do Decreto-Lei no 414/71, de 27 de Setembro, que entre outros aspetos instituiu a carreira de "técnicos terapeutas", que abrangia os fisioterapeutas. Esta carreira foi englobada no grupo de carreiras relativo a "profissionais com habilitação técnica devidamente titulada" em paralelo, por exemplo, com os técnicos de serviço social, e marca uma diferenciação profissional no âmbito da saúde. No mesmo diploma referem-se no artigo $4^{\circ}$ como carreiras de tipo 1: "carreira médica de saúde pública; carreira médica hospitalar; carreira farmacêutica; carreira de administração hospitalar; carreira de técnicos superiores de

\footnotetext{
${ }^{21}$ Portaria no 18523, de 12 de Junho de 1961, Diário do Governo, nº 135, I Série, 12 de Junho de 1961, p. 700.

${ }^{22}$ Portaria 18523, de 12 de Junho de 1961. Diário do Governo, I Série, nº 135, 1961, p. 701.

${ }^{23}$ Decreto-Lei no 413/71, de 27 de Setembro. Diário do Governo. 1a Série. 228(1961) p. 1406-1434. Este diploma pretendia reorganizar os diferentes serviços do Ministério da Saúde e Assistência de modo a permitir uma melhor capacidade de resposta perante as exigências sanitárias, promovendo uma melhor eficácia a nível da "saúde pública" e de "promoção social".
} 
laboratório". Nas carreiras de tipo 2 incluiam-se: "carreira de ensino de enfermagem; carreira de enfermagem de saúde pública; carreira de enfermagem hospitalar; carreira de técnicos terapeutas; carreira de técnicos de serviço social; carreira de técnicos auxiliares de laboratório; carreira de técnicos auxiliares sanitários" ${ }^{24}$.

No contexto da renovação cultural e científica da sociedade portuguesa depois do 25 de Abril de 1974 a Escola de Reabilitação do Alcoitão estabeleceu como objetivo a sua integração no ensino superior, uma vez que a formação era pós-secundária e tinha uma duração de 3 anos-letivos. Iniciou-se, assim, um processo de diferenciaçáo relativamente ao Centro de Medicina de Reabilitação do Alcoitão. Em 1975 foi criado o primeiro Estatuto provisório da Escola e o respetivo Conselho Diretivo provisório. Esta etapa marcou uma separação pedagógica entre a Escola de Reabilitação do Alcoitão e o Centro de Medicina de Reabilitaçáo de Alcoitáo sem, contudo, haver uma total separação financeira e administrativa.

Apesar de, em 14 de Outubro de 1977, ter sido criado o ensino superior de curta duração ${ }^{25}$ e dos esforços efetuados pela Escola, o objetivo de integração no ensino superior não se viria a concretizar ainda nesta fase. Pelo Decreto-Lei no 480/77, de 15 de Novembro de $1977^{26}$, “O Hospital de Sant'Ana, na Parede, e o Centro de Medicina de Reabilitação, em Alcoitão, estabelecimentos pertencentes à Santa Casa da Midericórdia de Lisboa, passam a depender da Direcção-Geral dos Hospitais e a reger-se, em todos os aspectos do seu funcionamento, pela legislaçáo vigente para os estabelecimentos hospitalares oficiais" 27 . Refere ainda o mesmo diploma, no artigo $3^{\circ}$ que "A escola de reabilitação, criada nos termos da Portaria n. ${ }^{\circ} 22034$, de 4 de Junho de 1966, é dotada de autonomia administrativa relativamente ao Centro de Medicina de Reabilitaçáo, em termos que serão objecto de regulamento a aprovar por portaria do Ministro dos Assuntos Sociais" ${ }^{28}$. Logo de seguida o mesmo Decreto-Lei indicada que "O actual regime da escola mantém-se enquanto não for aprovado o regulamento a que se refere o número anterior"29.

Esta passagem para a dependência do Ministério dos Assuntos Sociais, acaba por coincidir com a publicação da Carreira dos Técnicos Auxiliares dos Serviços Complementares de Diagnóstico e Terapêutica através do Decreto Regulamentar no 87/77, de 30 de Dezembro. Neste diploma inscreve-se o seguinte: "Artigo $1^{\circ}-1$ - É criada, nos termos do presente diploma e de harmonia com o mapa anexo, que do mesmo faz

${ }^{24}$ Decreto-Lei no 414/71, de 27 de Setembro. Diário do Governo. 1a Série. 228 (1961), p. 1436.

${ }^{25}$ Veja-se Decreto-Lei no 427-B/77, de 14 de Outubro. Este diploma refere no artigo $1^{\circ}$ que "É instituído o ensino superior de curta duração tendente à formação de técnicos especialistas e de profissionais de educação a nível superior intermédio". Mais adiante o mesmo diploma refere no artigo 3º, parágrafo 1 que "As escolas superiores técnicas terão como finalidade: a) Ministrar o ensino predominantemente técnico para formação de profissionais qualificados nos domínios da tecnologia industrial, da produçáo agrícola, pecuária e florestal, da saúde e dos serviços”.

${ }^{26}$ Decreto-Lei no 480/77, de 15 de Novembro de 1977. In: Diário da República, 1a Série. 264 (1977) pp. 2724-2726.

${ }^{27}$ Idem, $^{\text {art }}{ }^{\circ} 1^{\circ}$, p. 2725.

${ }^{28} \mathrm{Idem}, \operatorname{art}^{\mathrm{o}} 3^{\circ}-1$, p. 2725.

${ }^{29}$ Idem. 
parte integrante, a carreira de técnico auxiliar dos serviços complementares de diagnóstico e terapêutica, para vigorar nos serviços dependentes do Ministério dos Assuntos Sociais"30 Mais adianta o mesmo diploma que " 2 - A carreira criada no número anterior compreende, desde já, os profissionais seguintes: audiometristas, cardiografistas, dietistas, ergoterapeutas, fisioterapeutas, neurofisiografistas, optometristas, ortofonistas, ortoptistas, preparadores de laboratório, protésicos, radiografistas e radioterapeutas"31. Esta Carreira, que engloba os fisioterapeutas, representa a visão oficial do Ministério da Saúde de referenciar a formação destes profissionais ao Ensino Secundário e contraria a perspetiva da Escola de integração no Ensino Superior. Ao tempo não havia uma perspetiva coerente sobre o futuro do ensino na saúde, entre os Ministérios da Educação e da Saúde.

No seguimento da sua iniciativa de abrir o ensino superior de curta duração às profissóes na área da saúde, o Ministério da Educação convidou, em Janeiro de 1979 um perito britânico, profesor J. Mckie, para proceder a uma análise da situação e aconselhar as autoridades portuguesas. Este perito, após ter contactado com diversas entidades, produziu um relatório da sua visita "Report on a visit to Lisbon arranged by the British Council at the request of the Ministery of education and Culture, to investigate aspects of the education and training of paramedical technicians"32. Trata-se de um documento fulcral para compreender a situação do ensino destes profissionais e a posição divergente entre os dois ministérios, assim como a natureza distinta dos seus dois projetos ${ }^{33}$.

${ }^{30}$ Decreto Regulamentar no 87/77, de 30 de Dezembro. In: Diário da República, 1a Série. 301(1977) p. 3122(1).

${ }^{31}$ Idem.

32 "Report on a visit to Lisbon arranged by the British Council at the request of the Ministery of education and Culture, to investigate aspects of the education and training of paramedical technicians" 1979. Arquivo da SCML/CICMR/ CX002/Capilha 2.

${ }^{33}$ Pelo seu significado, e na medida em que é diretamente referenciada a Escola de Reabilitação do Alcoitão, transcrevemos aqui o ponto 7 desse relatório: "7 SUMMARY OF PRESENT SITUATION 7.1 I summarise the situation relevant to my assignment as follows. The Ministry of Education wishes to provide education and training for the technicians and auxiliary professions for health care as part of its plan "short cycle" higher education, with courses of five or six semesters entered at a level similar to university entrance level (six plus five or six years of schooling) and leading to a diploma. It envisages World Bank aid in the construction of special colleges (e.g. in Lisbon and Oporto). It has found a "prototype" of this type of course in the Medical Rehabilitation Centre at Alcoitão, where physiotherapists, occupational therapists and speech therapists are trained to internationally accepted standards. It has not drawn up this plans in co-operation with the Ministry o Social Affairs, having effected only formal contact with that Ministry. 7.2 The Ministery of Social Affairs has simultaneously begun to prepare plans for systematic training courses and qualifications for "middle" auxiliary technicians in hospitals. It has not consulted or involved the Ministery of Education, maintaining that this training of employees is a matter for the Ministery responsible for the hospitals which use them. Although the plans are not completed or approved, it seems that the courses may not fit the pattern of short cycle higher education preferred by the Ministery of Education, since entry may be allowed at a lower educational level and the duration of courses may be slightly shorter. The pattern of the courses at Alcoitáo would not seem to be preferred for more general application. 7.3. There is undisguised antagonism between the two Government Departments over his issue, with no effective dialogue at the working level. The focus of disagreement seems to be the level of secondary education required at the commencement of training: This is not unimportant, but it does not seem to me to be the first question to be tackled. " in Arquivo da SCML. 
A primeira questão que Mckie considera que deveria ser encarada era a do papel do Ministério da Educação na preparação de profissionais para trabalhar na área da saúde. A segunda, igualmente importante, e que se prendia com a primeira, era a do papel na prestação de cuidados de saúde que o Ministério da Saúde reservava para os técnicos e outros profissionais não médicos. O especialista Mckie partia de dois considerandos fundamentais: a vantagem de estes profissionais não serem "treinados" em função de um posto de trabalho específico mas sim de serem "educados" para que pudessem resistir às constantes mudanças tecnológicas e dos contextos de emprego; e em segundo, o desafio que se colocava a Portugal no contexto dos países europeus, em que a adequação aos modelos de formação e de exercício nestas áreas seria relevante.

O relatório, para além de outras recomendaçóes pertinentes, sublinhava a necessidade da partilha de responsabilidades dos dois Ministérios, neste tipo de ensino, e defendia claramente a sua inclusão no ensino superior de curta duração, tal como acontecia por toda a Europa, no caso concreto dos profissionais cujo contacto com os utentes era direto ("intimate") e continuado. Especificamente em relaçáo à formação de fisioterapeutas o modelo utilizado na Escola de Reabilitação do Alcoitão foi considerado, no relatório, como adequado ao padrão europeu da época.

As posiçóes deste perito internacional vinham ao encontro das teses defendidas pela Escola de Reabilitação do Alcoitão e pela Associação Portuguesa de Fisioterapeutas e constituíram, sem dúvida, uma arma fundamental na argumentaçáo contra os princípios que a Direção-Geral dos Hospitais vinha defendendo.

Ainda em 1979, o Ministério da Educação criou o Ensino Superior Politécnico e surgiram nos Institutos Superiores Politécnicos de Lisboa e do Porto, através do Decreto-Lei no 513-T/79, de 26 de Dezembro, as Escolas Superiores de Saúde.

\section{O papel da Escola de Reabilitação no contexto das Escolas Técnicas dos Serviços de Saúde (1980-1991)}

Em 1982 a escola passou a estar abrangida pela mesma legislação que regia as Escolas Técnicas dos Serviços de Saúde, de Lisboa, Porto e Coimbra, embora mantendo algumas particularidades de gestão administrativa e pedagógica ${ }^{34}$, passando a tutela Pedagógica da Escola para o Departamento de Recursos Humanos da Saúde, do Ministério da Saúde, permitindo-lhe manter o modelo de formação que vinha desenvolvendo. No artigo 2o do mesmo do diploma refere-se: "A Escola de Reabilitação do Alcoitão manterá as suas instalaçôes actuais e funcionará em ligação com o Centro de Medicina de Reabilitação do Alcoitão" 35 .

Após o processo de revisão curricular realizado em 1990 e desenvolvido no conjunto das quatro escolas nacionais atrás citadas, conduzido pelo Departamento de

\footnotetext{
${ }^{34}$ Decreto-Lei no 371/82, de 10 de Setembro. In: Diário da República. 1a Série. 210 (1982) pp. 2719-2721.

${ }^{35}$ Vide Artigo ${ }^{\circ}$ do Decreto-Lei no 371/82, de 10 de Setembro.
} 
Recursos Humanos do Ministério da Saúde, foram aprovados planos de estudos iguais a nível nacional, que passaram a vigorar obrigatoriamente em todas as escolas públicas. Neste processo, a liderança da revisão curricular do curso de Fisioterapia coube à Escola de Reabilitação do Alcoitão, pelo que o novo currículo pode ser entendido não como um corte, mas antes como um aperfeiçoamento do modelo entáo em vigor.

\section{O retorno à condiçáo de escola privada e a integraçáo no ensino superior (de 1991 à atualidade)}

Em 1991 iniciou-se uma nova fase da história deste estabelecimento de ensino com o seu retorno ao estatuto de natureza privada, sendo reintegrado na Santa Casa da Misericórdia de Lisboa. Com efeito, foi através do Decreto-Lei no 274/91, de 7 de Agosto $^{36}$, com a confirmação do Conselho de Direção, que se realizou essa reintegração. Manteve-se contudo a dependência financeira e administrativa do Centro de Medicina de Reabilitação do Alcoitão. No texto introdutório do referido diploma assinala-se a criação do Centro de Medicina de Reabilitação do Alcoitão em 1964 e reconhece-se que essa criação "permitiu a implantação e desenvolvimento de uma área da medicina que, até esse momento, se poderia considerar numa fase artesanal e praticamente desconhecida no País" ${ }^{37}$. No mesmo texto valoriza-se o papel de todos os que até àquele momento haviam trabalhado na Escola e sublinha-se que "granjearam-lhe reconhecido prestígio nacional e internacional" 38 . No artigo $10^{\circ}$ do mesmo diploma inscreve-se " 1 A Escola de Reabilitação, criada nos termos da Portaria no 22034, de 4 de Junho de 1966, é dotada de personalidade jurídica e autonomia técnica e reintegrada na SCML" ${ }^{39}$.

Inicia-se, entáo, o processo tendente à integraçáo da Escola no sistema educativo nacional, a nível do ensino superior politécnico e a preparação da sua individualização relativamente ao Centro de Medicina de Reabilitação de Alcoitão. Este movimento é coincidente com o da integração das escolas Técnicas dos Serviços de Saúde no sistema Educativo Nacional a nível do Ensino Superior Politécnico, o qual viria a efetivar-se pelo Decreto-Lei no 415/93, de 23 de Dezembro - que cria as Escolas Superiores de Tecnologia da Saúde de Lisboa, Porto e Coimbra.

A integração plena no sistema de ensino, a nível do ensino superior aconteceu em 1994, com a reconversão da Escola de Reabilitação do Alcoitão, em estabelecimento de ensino superior privado, com a aprovação dos planos de estudos, atribuindo o grau de bacharel, de acordo com o primeiro estatuto da Escola de Reabilitação do Alcoitão, ao abrigo da legislação em vigor.

A partir desta altura e já com o estatuto de escola de ensino superior politécnico devem assinalar-se, também, alguns marcos importantes. Assim, em 1995 foi aprovado e

\footnotetext{
${ }^{36}$ Decreto no 274/91, de 7 de Agosto. In: Diário da República. 1a Série. 180 (1991) pp. 3923-3925.

${ }^{37}$ Idem, p. 3923.

${ }^{38}$ Idem, p. 3923.

${ }^{39}$ Idem, p. 3925.
} 
realizado o registo do segundo estatuto da Escola Superior de Saúde do Alcoitão, ao abrigo da legislação em vigor. Três anos mais tarde, em 1998, foram publicados os Estatutos da Escola Superior de Saúde do Alcoitão e o regulamento da carreira docente em Diário da República - II Série - Aviso no 15 935/98 (2a série), no 232 de 08-10-1998.

Em 2000 foi autorizado o funcionamento dos cursos bietápicos de licenciatura e quatro anos mais tarde foi publicada a alteração aos Estatutos da Escola Superior de Saúde do Alcoitão, em Diário da República - II Série - Aviso no 3422/2004 (2a série) no 64 de 16 de Março. No ano letivo de 2007/2008 teve inicio a lecionação do mestrado em Reabilitação Neurológica - especialidade para fisioterapeutas, realizado pelo Instituto de Ciências da Saúde da Universidade Católica Portuguesa, em colaboração com a Escola Superior de Saúde do Alcoitão. A adaptação dos planos de estudos do curso de licenciatura ao Processo de Bolonha ocorreu no ano letivo 2008-2009.

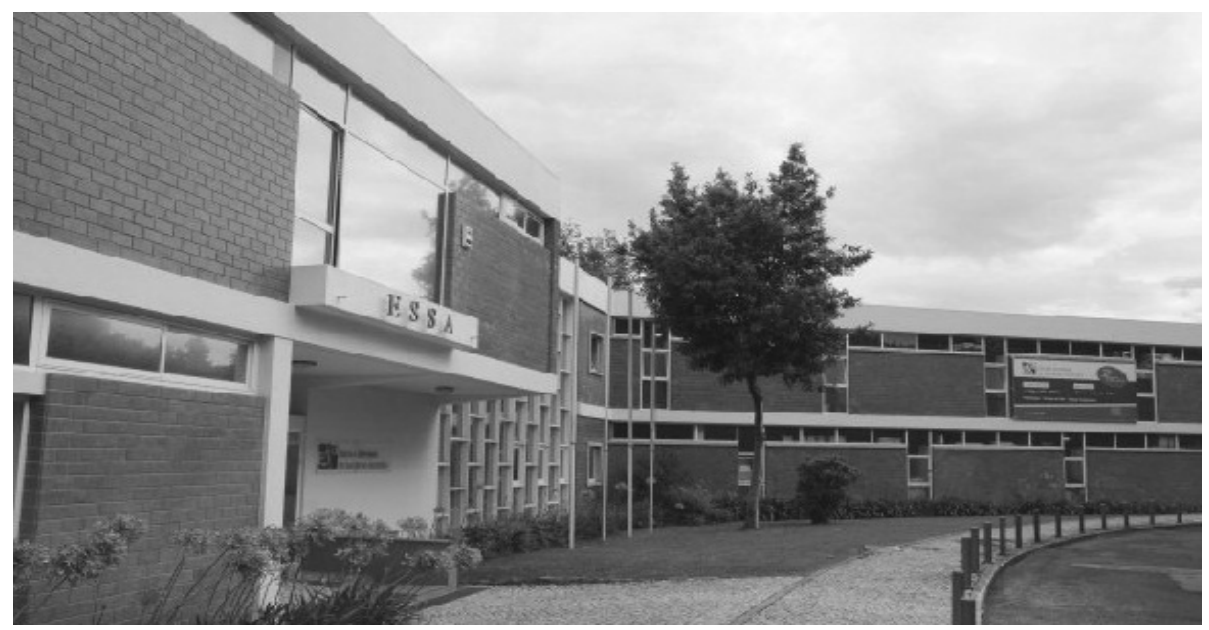

Imagem 4. Escola Superior de Saúde de Alcooitão

(In:www.ESSA.pt)

Com o Processo de Bolonha abriu-se a possibilidade de a Escola Superior de Saúde do Alcoitão iniciar de forma autónoma a lecionação de curso de mestrado em Fisioterapia, o qual seria autorizado a partir do ano-letivo 2009-2010. O atual estatuto da Escola Superior de Saúde do Alcoitão está já adequado ao novo regime jurídico das instituiçóes de ensino superior.

\section{Conclusão}

A construção do Centro de Medicina de Reabilitação do Alcoitão permitiu organizar a formação de fisioterapeutas, em Portugal, o que teve a sua continuidade até hoje, na Escola Superior de Saúde do Alcoitão, cumprindo critérios nacionais e internacionais. 
A história desta Escola constitui um valioso contributo para a construçáo da identidade da profissão de fisioterapeuta se pensarmos que a formação especializada, intensa e extensa constitui um tópico essencial na formaçáo de um grupo profissional. Também se deve assinalar, neste contexto, a existência de legislação própria para o exercício profissional e o surgimento de associaçóes profissionais. Com efeito, todos estes requisitos se cumpriram com alicerces seguros. E, neste artigo, é de destacar que historicamente a mais sólida base de apoio tem sido o conjunto de progressos científicos e técnicos na área que se foram plasmando na formaçáo dos fisioterapeutas até alcançar o nível recente e de grande exigência de ensino superior politécnico. 


\section{REFERÊNCIAS BIBLIOGRÁFICAS E DOCUMENTAIS}

\section{Arquivos consultados}

Arquivo da Santa Casa da Misericórdia de Lisboa

SCML. Deliberaçóes de mesa, 1957-1958. Cota: sem cota

SCML. Centro de Medicina de Reabilitação - Comissão Instaladora, Livro de Actas 1961-1966. Sem número de páginas. Cota: SCML/CICMR/01/01/LV001.

Documentos avulso

SCML. Centro de Recuperação de Diminuídos Motores (1955-1957). Carta "urgente" do Provedor, Dr. António Madeira Pinto para o Dr. José de Melo e Castro, subsecretário de Estado da Assistência Social de 30 de Julho de 1955. pp 2-4. Cota: SCML/CICMR/CX01/Capilha 01.

SCML. Assuntos relacionados com o Centro de Medicina do Alcoitão. Relatório do McKie "Report on a visit to Lisbon arranged by the British Council at the request of the Ministery of Education and Culture, to investigate aspects of the education and training of paramedical tecnhicians" 1979. SCML/CICMR/ CX002/Capilha 2.

\section{Legislaçáo}

\section{Diário do Governo}

"Decreto Auctorizando a creação de um laboratório de analyse clinica no referido hospital [Hospital Real de S. José] , e aprovando a respectiva organização, que ao mesmo decreto vae appensa”. Diário do Governo. 293, de 27 de Dezembro de 1901

Relatorio do enfermeiro-mor José Curry da Camâra Cabral. Diário do Governo. 293, 27 de Dezembro de 1901

Decreto-Lei no 28794, de 12 Julho de 1938. Diário do Governo. 1a Série. 150. 1938, pp. 10331040.

Decreto-Lei no 36507. Diário do Governo. 1a Série. 216. 1947, pp. 879-887.

Portaria 14416, de 9 de Junho de 1953. Diário do Governo. 1a Série. 121. 1953., pp. 819-828.

Portaria 18523, de 12 de Junho de 1961. Diário do Governo. 1a Série. 135. 1961, pp. 700-702.

Portaria no 22034, de 4 de Junho de 1966. Diário do Governo. 1a Série. 131. 1966, pp. 10631064 .

Decreto-Lei no 413/71, de 27 de Setembro. Diário do Governo.1a Série. 228. pp. 1406-1434.

Decreto-Lei 414 /71, de 27 de Setembro. Diário do Governo. 1a Série. 228. pp. 1434-1445.

\section{Diário da República}

Decreto-Lei no 427-B/77, de 14 de Outubro

Decreto-Lei no 480/77, de 15 Novembro. Diário da República. 1a Série. 264. pp. 2724-2726.

Decreto Regulamentar no 87/77, de 30 de Dezembro. Diário da República. 1a Série. 301. pp. 3122(1)-3122(2).

Decreto-Lei no 513-T/79, de 26 de Dezembro. Diário da República. 1a Série. 301. pp. 3350(60)$3350(64)$

Decreto-Lei no 371/82, de 10 de Setembro. Diário da República. 1a Série. 210. pp. 2719-2721.

Decreto-Lei no 274/91, de 7 de Agosto. Diário da República. 1a Série. 180. pp. 3923-3925. 
Decreto-Lei no 415/93, de 23 de Dezembro. Diário da República. 1a Série. 298. pp. 7136-7137. Aviso $n^{\circ} 15935 / 98$ (2a série), de 8 de Novembro.

Aviso no 3422/04 (2a série), de 16 de Março.

\section{Bibliografia}

ARRUDA, Luísa Arruda; SOUSA, Rui Morais de - Centro de Medicina de Reabilitação de Alcoitão. História do Projecto de Medicina de Reabilitação. A arquitectura e a arte. Lisboa: Santa Casa da Misericórdia de Lisboa, 2006.

BARCLAY, Jean - In good hands: the history of the Chartered Society of Physiotherapy, 1894-1994. Oxford: Butterworth-Heinemann, 1994.

CARVALHO, Rómulo de - História do Ensino em Portugal: desde a fundação da nacionalidade até ao fim do regime de Salazar-Caetano. Lisboa: Fundação Calouste Gulbenkian, 1986.

FONSECA, João Pedro da - História da fisioterapia em Portugal (da origem a 1966). Lisboa: Mestrado em Fisioterapia, Instituto Politécnico de Lisboa - Escola Superior de Tecnologia da Saúde de Lisboa, 2012.

GRANGER, F. B. - "The development of physiotherapy”. Physical Therapy. 1:56(1976) pp. 13-14.

GOMES, Ana - Claudina de Freitas Guimaräes Chamiço. Lisboa: Ediçâo da SCML, 2010.

LOPES, António Manuel - Desenvolvimento pessoal e profissional dos fisioterapeutas: papel e modalidades da formação contínua. Dissertação apresentada à Universidade de Lisboa Faculdade de Psicologia e Ciências da Educação, para obtenção do Grau de Mestre em Ciências da Educação, área de especialização Pedagogia na Saúde, 1994.

LOPES, António Manuel; RODRIGUES, Maria Armanda - "Origens e Evolução da Fisioterapia: Pespectivas Sobre o Contributo Militar”. In: Actas do XVI Colóquio de História Militar. Vol. I. Lisboa: Comissão Portuguesa de História Militar, 2007, pp. 323-404.

MOFFAT, Marilyn - "A history of physical therapist education around the world". Journal of Physical Therapy Education, Vol. 26, No. 1 (2012)

McCOY, P. - Physiotherapy: A profession?. Belfast: Dissertation submited as a part fulfilment for the degree of Master of education at Queen's University, Belfast, 1987.

RODRIGUES, Maria Armanda; PITA, João Rui; PEREIRA, Ana Leonor - "As ciências farmacêuticas e fisioterápicas na revista Fisioterapia (1929-1939)”. In: FIOLHAIS, Carlos; SIMÓES, Carlota; MARTINS, Décio - Congresso Luso-Brasileiro de História das Ciências. Universidade de Coimbra, 26 a 29 de Outubro de 2011. Livro de Actas, Coimbra, 2011. pp. 943-957.

RODRIGUES, Maria Armanda; PITA, João Rui; PEREIRA, Ana Leonor — “A fisioterapia em Portugal entre as duas guerras na revista Fisioterapia (1929-1939)". In: XIX Colóquio de História Militar. 100 anos do regime republicano. Politicas, rupturas e continuidades. Actas., Lisboa: Comissão Portuguesa de História Militar, 2011. pp. 689-702.

RODRIGUES, Maria Armanda; LOPES, António Manuel - "O Contributo da Escola Superior de Saúde do Alcoitão na História da Fisioterapia e da Formação de Fisioterapeutas em Portugal”, IX Congresso Luso Brasileiro de História da Educação: Rituais, Espaços \& Patrimónios Escolares, Atas. Instituto de Educação da Universidade de Lisboa, Lisboa, 2012. pp. 2889-2902.

SERRÃO, Joaquim Veríssimo - A Misericórdia de Lisboa. Quinhentos anos de Historia. Lisboa: Livros Horizonte e Santa Casa da Misericórdia de Lisboa,1998. 
URBANO, Cláudia Susana Valadas - O ensino politécnico em Portugal: a construção de uma identidade perante os desafios de mudança (entre o final do século XX e o início do século XXI). Lisboa: Tese de Doutoramento em Sociologia - Faculdade de Ciências Sociais e Humanas Universidade Nova de Lisboa, 2011. 